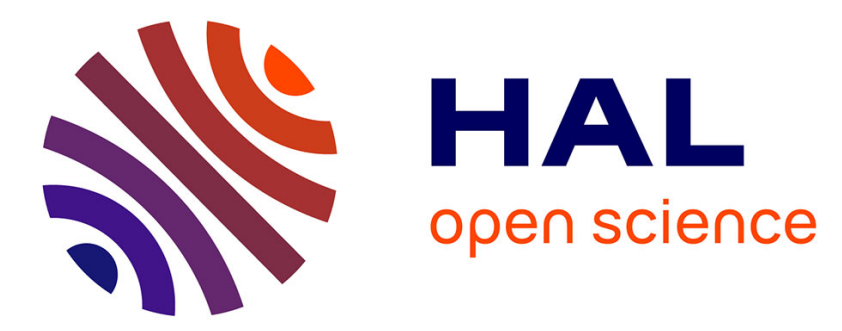

\title{
TRIZ and Intellectual Property to Strengthen the Start-Up Spirit
}

Pierre Saulais, Pascal Sire, Eric Prevost, Yves Guillou, Alain Riwan

\section{To cite this version:}

Pierre Saulais, Pascal Sire, Eric Prevost, Yves Guillou, Alain Riwan. TRIZ and Intellectual Property to Strengthen the Start-Up Spirit. 18th TRIZ Future Conference (TFC), Oct 2018, Strasbourg, France. pp.193-203, 10.1007/978-3-030-02456-7_16 . hal-02279760

\section{HAL Id: hal-02279760 \\ https://hal.inria.fr/hal-02279760}

Submitted on 5 Sep 2019

HAL is a multi-disciplinary open access archive for the deposit and dissemination of scientific research documents, whether they are published or not. The documents may come from teaching and research institutions in France or abroad, or from public or private research centers.
L'archive ouverte pluridisciplinaire HAL, est destinée au dépôt et à la diffusion de documents scientifiques de niveau recherche, publiés ou non, émanant des établissements d'enseignement et de recherche français ou étrangers, des laboratoires publics ou privés. 


\title{
TRIZ and Intellectual Property to strengthen the start-up spirit
}

\author{
Pascal Sire ${ }^{1}$, Eric Prevost ${ }^{2}$, Yves Guillou ${ }^{3}$, Alain Riwan ${ }^{4}$, Pierre Saulais ${ }^{5}$ \\ ${ }^{1}$ innoppie \& VP TRIZ France, Strasbourg, France - pascal.sire@innoppie.com \\ ${ }^{2}$ Oracle Corp \& President TRIZ France, Paris, France - president@trizfrance.org \\ ${ }^{3}$ Guilbert EXPRESS \& Secretaire TRIZ France, Paris, France - secretaire@trizfrance.org \\ ${ }^{4}$ CEA, LIST, Interactive Robotics Laboratory, Paris, France - alain.riwan@cea.fr \\ ${ }^{5}$ Mines Telecom Institute, Paris, France - pierre.saulais@telecom-em.eu
}

\begin{abstract}
How can start-ups benefit from business innovation good practices while enforcing the link between invention, innovation and intellectual property (IP) to contribute to this vital discussion for the survival of our industries? Some experts of the TRIZ France association drawn from their practical experiences a path to illustrate the methodological and practical contributions of the Theory for inventive problem solving (TRIZ). This illustration highlights a specific focus on businesses where the "start-up spirit" facilitates ideation and accelerates the production of innovative products and services.
\end{abstract}

Keywords: Innovation design, intellectual property, start-up, TRIZ.

\section{Introduction: inventive design and start-up spirit}

A start-up is "a human institution designed to create a new product or service under conditions of extreme uncertainty" [1], characterized by four conditions: high potential growth, use of a new technology, financial need and new market difficult to evaluate.

The start-up spirit is a mode of operation that stimulates innovation, creativity, perhaps even rebellion and strengthens team spirit, spontaneity, the risk of failure, agility and quick adaptation.

Important: "Start-up $=$ disruption, growth and uncertainty and start-up spirit $=$ pioneering spirit"

The purpose of this paper is therefore first to synthetize an approach able to solve technical problems blocking the functional evolution of a technical object, so as to advance the latter towards the ideality through successive optimizations in innovation trajectories that will be identified. The second purpose is to explore how to include this approach in stakeholder strategies (incubators and start-ups, innovative firm) in order to develop it in the start-up spirit as an application of innovation management.

This paper will begin by situating the problem-solving approach associated with TRIZ as a major phenomenon in the history of scientific methods $(\S 2)$. Then, it will focus on highlighting the main elements constituting the basis of the mental progression of the methodology whose guiding thread is made of postulates of technical systems evolution leading to the principle of analogy used by TRIZ ( $(3)$. 
Paragraph 4 tries to link the TRIZ principles with stake holders strategy. The purpose of paragraph 5 is to illustrate the above considerations with case studies regarding an industrial group and start-up environment. The conclusion summarizes the lessons learned, limitations and perspectives of the paper.

\section{TRIZ Historical Background}

TRIZ, invented by Altshuller [2], is the Russian acronym for an expression ("Teoriya Res-heniya Izobreatatelskikh Zadatch") meaning "Theory of the resolution of inventive problems". It is a set of methods and tools, originally associated with the techniques of the years 1950-1960, whose objective is to help solve technical problems by systematizing the identification of models of solutions and of intellectual processes for inventive problem solving.

TRIZ tools are used particularly in the car industry and in aeronautics, but applications to other sectors are common [3]. They allow both to solve problems of inventiveness, to prepare patent filings but also to initiate the implementation of R \& D strategies [4].

TRIZ is to innovation what Lean and SixSigma are to continuous improvement and, just as Toyota is the global reference Lean, Samsung has quickly become the world TRIZ reference. Its exceptional growth in innovation and in economic and commercial performance has allowed the South Korean conglomerate to become in a few years a leader in many fields (electronics, household appliances,...), largely through the systematic implementation of TRIZ since 2007 in all the layers of its organization, as main method of innovation of company, which allowed him to realize a strong growth of its turnover.

Other large groups are now massively using TRIZ to increase the efficiency of their innovation initiatives (Siemens, General Electric, etc.). The TRIZ process is wordly recognized as pragmatic and effective for the development of innovation in business and, like Lean and SixSigma, requires a rigorous and repetitive corporate approach to be effective.

The European TRIZ Association (ETRIA) set up a survey to measure the state of diffusion of TRIZ in the world. The results show that companies applying TRIZ observed a gain in the quantity but also in quality of new ideas. The study also shows that the inventive concepts originating from TRIZ are often subject to patenting. Likewise, most of the companies that have experimented with TRIZ want to set up their internal deployment [5].

\section{TRIZ Basics}

\section{1 "Why" rather than "How"}

The production of inventive ideas is the starting point of innovation, so much necessary in the current economic context. The performance requirement obligation imposes the implementation of a fruitful and rational process for the emergence of breakthrough ideas, able to better fix current and future problems. 
In order to systematize the process of searching for concepts, patentable invention and value creation, it is necessary to understand WHY (there is a problem) rather than immediately looking for HOW (finding the solution). The How is a "reflex" question, whereas the Why is a "reflective" question [6].

TRIZ infers that the problems encountered during the design of a new business model, product or service present analogies with others and that similar solutions could be applied [2]. The result of the systematic analysis of patents allowed Altshuller to highlight three postulates, on which will be based the principle of analogy:

- The solutions are similar in most of industrial and scientific domains;

- Models of technical evolution are repeated in most of industrial and scientific domains;

- Innovations can use scientific effects coming from other technical fields.

Thanks to these outcomes, Altshuller formalized his inventive problem solving approach by reformulating the problem to better solve it $[7,8]$, without any direct resolution of the initial problem, but through the transformation into a generic problem by abstraction.

\subsection{Evolution characterized by $S$ curve}

According to Altshuller's postulates, the most of technical systems in our environment seem to evolve as shown by the curve in Figure 1, where horizontal axis represents time and axis represents a vertical factor related to the performance of the technical system.

\begin{tabular}{|c|c|c|}
\hline STATIC LAWS & KINEMATIC LAWS & DYNAMIC LAWS \\
\hline $\begin{array}{l}\text { 1. Integrality: } \\
\text { The system } \\
\text { should be complete } \\
\text { 2. Energy } \\
\text { conductibility: } \\
\text { The energy chain of } \\
\text { the system should be } \\
\text { complete. } \\
\text { 3. Coordination } \\
\text { of the rythm: } \\
\text { The different parts of } \\
\text { the system should be } \\
\text { coordinated }\end{array}$ & $\begin{array}{l}\text { 4. Increasing } \\
\text { of ideality: } \\
\text { The utility of the system } \\
\text { grows quicker than its } \\
\text { countereffects. } \\
\text { 5. Uneven development: } \\
\text { The different parts of } \\
\text { the system evolve on } \\
\text { different directions } \\
\text { 6. Transition to the } \\
\text { super-system: } \\
\text { The system can not } \\
\text { continue to evolve. } \\
\text { It take part as component } \\
\text { of a more } \\
\text { complete system. } \\
\text { GROWTH }\end{array}$ & $\begin{array}{l}\text { 7. Transition from } \\
\text { macro to } \\
\text { micro level: } \\
\text { The useful function } \\
\text { of the system is achieved } \\
\text { to microscopical } \\
\text { or molecular level } \\
\text { 8. Increasing of } \\
\text { the system dy namism: } \\
\text { The system become } \\
\text { more adaptive. } \\
\text { it is easily controllable. }\end{array}$ \\
\hline & & Time \\
\hline
\end{tabular}

Fig. 1. TRIZ - Evolution characterized by S curve (grey curve in foreground) and general 
evolution laws [table in background) (Source: [9])

Figure 1 can decomposed into three main parts [10]:

- The first part represents the beginning of the technical system life, young and very perfectible and with fast improvements.

- The second part, almost linear, corresponds to the optimization of the technical system, which tends to lead to a synthesis, by successive simplifications.

- The third part corresponds to the end of the evolution of the technical system, arrived at maturity and stabilized at an optimum.

\subsection{General evolution laws}

The real discovery that emerges from these observations by the systematic analysis of patents is that these tendencies are highly repeated, that is, the technical system invariably evolves by following them.

Evolution trends characterizing the $\mathrm{S}$ curve are usually presented in three groups (Figure 1, table in background). Each group has a very specific role and is applied according to the stage of evolution of the technical system:

- The three static trends are located at the beginning of the S curve. The technical system stammers and tries to fulfill its main function while adjusting and harmonizing the operation of its various components.

- The three kinematic trends go with the technical system according to its evolution on the S-curve. The efficiency of the system improves, the subsystems are harmonized and the technical system can in some cases make a transition to integration into an higher order technical system (called super-system).

- Dynamic trends are the last to be followed before the curve change. The technical system is becoming more and more controllable: new technical systems are emerging, tending to supplant the existing technical system. These are at odds with the initial technical system and are, for their part, at the beginning of their "S-curve".

Each law is associated with an evolution trend:

\# 1: Necessary and sufficient conditions for the emergence of a new viable system

\# 2: Proper circulation of energy flows

\# 3: Coordination of the rhythm of the parts for a joint work

\# 4: Trend towards increase of ideality level

\# 5: No weak link in the different parts

\# 6: Trend towards integration into a higher order system

\# 7: Transition of each means from the macroscopic level to the microscopic level

\# 8: Adaptation to external constraints

\subsection{Exploitation of evolutionary trends to put the principle of analogy into action}

Evolutionary trends are a great tool for benchmarking products, functions, technical systems, based on the evaluation of the maturity of the technical system through evolution trends [11].

First, their use makes it possible to estimate the positioning of the technical system analyzed through criteria specific to each of the eight general trends, based on the 
notion of observation point, on a deeper analysis than a mere intuition. Thus, the analysis of the system according to the first general trend [\# 1: Definition of the necessary and sufficient conditions for the appearance of a new viable system] makes it possible to check that nothing is missing to achieve the main function, then that the sixth general trend [\# 6: Trend towards integration into a higher order system] makes it possible to ask in which super-system can the system migrate and under which conditions.

The technical system studied can therefore be examined by general trends, based on some references, among which:

- The previous technical system that we wish to change;

- Competitive products performing a similar function;

- The "ideal" system in view of the general trend examined;

- Technical systems from other technical fields, better satisfying certain general trends, potentially transposable;

- Nature (bio-mimicry)

Finally, once the various evaluation criteria have been established, it is interesting to be able to group these results graphically, while keeping in mind the system maturity:

- Synthesize the results obtained on a single schema;

- Follow the evolutions during the design;

- Predetermine product schemas;

- Manage the system evolution, over several generations, if needed.

\section{$4 \quad$ TRIZ seen as a technique of creativity}

\subsection{How can TRIZ be defined?}

TRIZ has been defined in many different ways [12]:

- A theory, which is established on objective trends of technology evolution; TRIZ describes the process of new technology creation by mankind [13]. ARIZ [acronym for the Russian phrase "Algorithm for Inventive Problem Solving"] had features of universality; it was also starting to be used by researchers for problem solving in science and arts [14]. Because of its uses in arts, sciences, nature, etc., many ideas and tools of TRIZ could be used to develop theories for non-technological problem solving [15].

- A science and an art [16]

- A science, which studies evolution of technological systems, and develops methodology for synthesis, development and prognosis of such systems [17]

- A set of concepts. These concepts do not create the whole unity, in contrast to many applied methodologies and theories. The knowledges and concepts, which are included in TRIZ, may be considered as art [18].

According to [19], TRIZ is above all the empirical approach of a technique of creativity applied to problem solving, based on a methodological formalization and instrumented by a set of tools. Fifty years after the initial work of Altshuller, the TRIZ approach has been theorized as part of the overall problem-solving procedure aimed 
at translating the logic of the transitions between contradictions [20], inspired from solutions from other technical fields. However, this principle of analogy is not itself theorized in the method [19].

\subsection{Exploiting the principle of analogy}

Associated with TRIZ, a methodology able to solve technical problems blocking the functional evolution of a technical object consists of a heuristic approach aimed at solving technical problems and based on the postulates of technical systems evolution, postulates resulting from the compilation of a large number of patents. TRIZ is therefore a systematic method of creative problem solving, intense in knowledge and exploiting the principle of analogy [3, 20,21]. This principle suggests exploring generic solutions, borrowed from other domains, not yet applied to the particular problem. The importance of TRIZ in the sense of problem solving techniques comes from its nature of meta-methodology deployable in many fields of knowledge: indeed, TRIZ gathers reasoning orientations able to structure a mental process of problem solving [19]. TRIZ method is instrumented by ARIZ, which constitutes its operational instantiation in its proper methodological sense [19]. ARIZ stands for the acronym of the Russian expression "Algorithm for Inventive Problem Solving". [17, 22]

\subsection{TRIZ Approach and stakeholders strategy}

We have seen that the TRIZ approach came from the systematic analysis of patents of invention to tend towards a method to learn how to invent and that the strategy of problem solving must gradually reduce the area of research instead of increasing the number of variants according to a convergent approach which makes it possible to reformulate the problem to better solve it. It is necessary, in fact, to understand why (there is a problem) rather than immediately how (find the solution). Thus, by abstraction and in the form of contradictions, a problem is obtained which is independent of the technical field of the initial problem, which makes it possible to appeal for its resolution to scientific effects outside the initial technical field.

To build on the proven methods and practices of large groups, the authors wish to recall the following recommendations from their own experience:

- Start by "killing the myth" of the genius doing business by looking for the brilliant and inspired idea, but use a robust procedure of creativity to be ready to "jump on the next wave".

- Then put in place the right business environment, translate the strategic vision of the project leader into timing, adapt a different point of view by modeling the ideal, connect innovations with the strategy while being consistent with the customer experience and accelerate the "serial innovation" capability using the system's value chain model. By explaining to the young leader the notions of ideality and contradiction, allow him to keep in mind throughout his innovation process that the value chain of the start-up is closer to the "ideal final result" despite the necessities of everyday life. According to the experience of the authors, this pragmatic and effective support is done with the project leader or the management team in half a day, as soon as the start-up is ready to question and to revisit its model. [23] 
- Finally, a regular reporting (face-to-face or remote) allowing considering and program the next steps in order to be medium-term efficient and to attract potential investors.

\section{$5 \quad$ Case studies}

The object of the present paragraph is to illustrate the above considerations with case studies, extracted from an industrial group and start-up environment.

As seen in the first case study, by deconstructing a job into universal customercentric steps from beginning to end, a big company gains a complete view of all the points at which an employee might desire more help from a product or service-namely, at each step in his/her job; with a job map in hand [24], the company can analyze the biggest drawbacks of the products and services customers currently use, and TRIZ can quickly help solve them.

In the context of advanced innovation design approach, the second case study shows that a small new start-up can compete with big companies it deals with, while combining several existing known business principles [25] (as TRIZ does for problem solving) like open business model $\left(\mathrm{N}^{\circ} 32\right)$ and integrator $\left(\mathrm{N}^{\circ} 23\right)$ to leverage customer data $\left(\mathrm{N}^{\circ} 25\right)$. As detailed, the key issue for the start-up was to efficiently manage the IP.

With such methodological and business toolkits implementing inventive principles, knowing the past helps in creating the future. The proposed step-by-step process was detailed earlier [27] and got resonance with the start-ups using it.

\subsection{Use of the start-up spirit within an industrial group}

One company wanted the TRIZ France association to organize a two-hour workshop with a management and engineering school to innovate with students and employees of the company, on the theme of the computerization of tasks for operators with nopaper transmission of production orders and procedural instructions. To one of the mixed working groups (students, employees) led by an expert from the TRIZ France association, the expert asked to concentrate the group's reflection, not on the solution imagined by the client, but on the question expressed as: what is the best way to integrate software on PC or tablet provided to the operator?

With the first tool, "Day work Mapping", the participants described their vision of the operator's life in a typical day, after defining, with the help of the operator representative, the profile of the operator as observed in his daily work. Then, the group identified the most important questions: getting the right workbook for the right procedure, reading, understanding, memorizing and applying the instructions of the procedure, performing the self-check of the job, saving the job as done, and then go back to the first step for the next action.

Despite the explicit request of the large company to start immediately working on its own suggestions for solutions, this type of start-up approach has helped to "get out of the box" and redefine "in a bottom up" way the tasks of the operator to improve his work. Having not only automated some of his tasks with a tablet or a PC, the 
approach mostly reviewed the organization of his work by reordering tasks or eliminating unnecessary gestures to give back meaning to his daily work.

The challenge was then to understand the real problem to be solved and to identify the contradictions. With the second tool, "TRIZ Visualization", the group moved on to improving the lives of the operators by now actually searching for the "paperless" solution desired to support the manufacturing process. It turned out that the real problem to be solved was to get a heavy workbook with more than 200 pages, to bring it to your workstation and to flip through it for a long time before finding the right chapter and instructions to read.

Using some TRIZ methods (mainly the "Operation time" and the "Operation zone"), the question has been broken down into contradictions: the workbook must be heavy and light! As a matter of fact it should contain detailed information but easily accessible down to the right level and should not require too much effort yet without any detrimental simplification. Then the study of resources shown that the pictures and diagrams were the most effective support for instructions and that the screen of the standard PC was the most adapted media. The lesson learned from the second workshop is that visualization is a very powerful tool to help participants understand the underlying characteristics of an object or concept, in order to build their own mental representation of this object in real life.

With the conflict resolution guide to support the mental process, the team, heterogeneous, not previously trained in the TRIZ method, but guided "without his knowledge" by the expert (as "natural TRIZ thinkers" [26]), was able to effectively focus on solving the proposed problem. Formal implicit guidance helped the group not to diverge from the real problem to be solved and facilitated its concentration on its resolution. In addition, it helped demonstrate why the problem existed and how it was solved by allowing the reverse reading of the mental process.

As initially requested by the company, the problem was easily reformulated, better understood by the employees, and a solution was found with not trained participants in less than 2 hours.

\subsection{Start-up and need for protection by Intellectual Property}

For several years, the authors have been wondering about what TRIZ could do for young companies (validation of first ideas, improvement of concepts, strengthening of protection) and presented, in an international conference, the state of their experiments within a French incubator to train some start-ups in the TRIZ spirit [27].

TRIZ could bring this value differentiating them from incubators and their incubated start-ups, to help them understand what they do (systemic representation), give them a medium-term vision (trends of evolution) and thus guide them on the important aspects (resolution of contradictions) in terms of market, product or service innovation: this pragmatic way of pooling learning would give them a useful competitive advantage.

Guided by one of the co-authors for a year, the start-up adopted a strategy between the need for openness and the need for protection. This guidance went from the first successes to start-up competitions to funding difficulties (lack of seed funding), to 
industrial partnerships and to the INPI pre-diagnosis [28]; INPI is the French IP Office.

The purpose of the project is to develop and distribute an open-hardware connected object for the smart management of lighting and public infrastructure. It is a question of adapting the lighting to situations of use (road or city) in order to characterize a situation of danger or a zone of shade (preprogrammed or controlled light effects) to facilitate and secure the circulation of the vehicles and pedestrians (night path, light warning, tracking light or "white wave").

What are the Intellectual Property issues of this start-up emblematic of these entrepreneurs of the new economy, which combines elements existing on the market (industrial or public lighting managers, ...) with an agile development mode and participatory (local and strategic partnerships) while keeping the "core of the system" secret [29]?

In its pre-diagnosis, the INPI has identified several IP needs / constraints for the start-up: relationships already established with major players, subcontractors or strategic partners, implementation of a demonstrator for public lighting of a municipality, "network intelligence" (heart of innovation and intellectual property), "big data" analysis and formatting of dashboards. The INPI has validated and recommended a combination of its intellectual capital protection tools: search (regular competitive searches via esp@cenet from the European IP Office), dating (regularly done for two years via a dedicated Facebook page), secrecy and confidentiality (particular contract via business lawyer), contractual practices (occasionally via a business lawyer), filing of trademarks (authorization in progress) and filing of patents (evaluation of the connected robot).

The inventive design approach can therefore help the start-up to establish a medium-term vision to subtly pace its innovations on the market according to the maturity of its offer, that of its competitors and the desire of its customers to buy their products or services.

Facing the "openness versus protection" dilemma, the start-up benefited from a free resource (INPI pre-diagnosis) which listed the usual "SME versus large group" constraints in terms of intellectual protection, and which transposed by analogy the most meaningful recommendations for the start-up in less than half a day.

\section{Conclusion}

The present paper has studied an approach able to solve technical problems blocking the functional evolution of a technical object. This TRIZ methodology was located as a phenomenon of technical thought born in the middle of the 20th century, still relevant two generations later, devoted to the methodological approach of technical invention as a method of creativity in the framework of inventive resolution of technical problems. The basis of the method consists of postulates of the evolution of technical systems, which is based on the principle of analogy used by TRIZ. It is put into action through the identification and analysis of evolution trends to give them a predictive sense in terms of the course of time considered as an element of functional 
and technical maturation. Case studies, in an industrial group or start-up environment, have illustrated the formal considerations previously developed, in particular for an in-depth analysis of the operational start-up of a start-up.

It was thus given to the reader the power of a formal logic of problem solving inscribed in the prism of evolution, participating in an approach looking for, on the one hand, by abstraction, a specific genericity able to generate other decontextualized applications by the principle of analogy and, on the other hand, an optimal implementation. These two fundamentals fully characterize the field of knowledge, and it is not surprising that the empirical construction of such a methodology, largely based on the founding principles of theories of knowledge as well as the usual considerations of general methods for problem solving, inspired later theorization. The success of the very broad deployment in the industry is therefore due, among other things, to the simplicity of the few logical reasoning, which hide from the user the formal depth of theories later formulated that justify them.

With the concrete cases solved within a few hours of the big company trying to think with the "start-up spirit" and of the open hardware start-up struggling to exist in the complex world around it, the reader will have noted that the formalism of problem solving can extend to many of the young entrepreneur's decision making and therefore this formalism of mental exploration is itself a state of mind, rigorous and oriented toward the search for progress, applicable by the same principle of analogy as that which is at the heart of the TRIZ method.

Engineers and practitioners, the co-authors are much more focused on the core of the methodology and its concrete applications than on the very theorization that this methodology inspired. They do not address the limitations brought to light by this theorization that they leave to researchers specialized in the subject.

Moreover, the format of the paper did not exhaust the subject of the potential contribution of the TRIZ method to start-up entrepreneurs, which of course means that the prospects it opens up concern of this field of potential for young start-ups.

\section{References}

1. Ries E (2012) The Lean Startup, Pearson, 2012

2. Altshuller G (1988) Creativity as An Exact Science: The Theory of the Solution of Inventive Problems. New York, Gordon \& Breach

3. Leung W, Yu K (2007) "Development of online Game-Based Learning for TRIZ". In K.C. P.-K. HUI, Technologies for e-learning and Digital Entertainment (Vol. 4469), VOLUME 4469 OF LECTURE NOTES I: Springer

4. Dubois S (2009) "Comparison of non solvable Problem Solving Principles issued from CSP and TRIZ”. In G. CASCINI, Computer-Aided Innovation (CAI) (Vol. 277), Springer

5. Cavalucci D (2012) Une théorie de l'invention en support des activités R \& D : Outil et mise en œuvre par l'exemple. Techniques de l'Ingénieur

6. Guillou Y (2012) Le comment et le pourquoi, Consulté le 2211 2016, sur http://trizexperience.blogspot.fr/2012/06/le-comment-et-le-pourquoi.html

7. Riwan A (2013) "TRIZ helps blind people to find their ways in subway stations", TRIZ Future Conference 2013, Paris, France 
8. Riwan A (2014) “Enhanced Experience and Safety in interactive Robots”, Global TRIZ Conference 2014, Seoul, Korea

9. Seradinski A, Jadaud D (2011) «TRIZ : les notions de base », Revue Technologie (172), 2011

10.Guillou Y (2011) La courbe en S, Consulté le 2211 2016, sur http://trizexperience.blogspot.fr/2011/04/la-courbe-en-s.html

11. Guillou Y (2014) L'évaluation au travers des lois d'évolution, Consulté le 2211 2016, sur http://triz-experience.blogspot.fr/2014/08/levaluation-au-travers-des-lois.htm

12.Zakharov A (2008) Explore the Future of TRIZ with the Trends of Evolution, The TRIZ Journal, March 5, 2008

13.Lenyashin V and Kynin A. What is TRIZ? http://www.metodolog.ru/01008/01008.html

14.Altshuller G (1986) History of ARIZ Development. http://www.altshuller.ru/world/eng/

15.Altshuller G (1988) Summary “TRIZ-88."http://www.altshuller.ru/world/eng/

16.Mitrofanov V. My TRIZ Understanding. http://www.metodolog.ru/01291/01291.html

17.Devoyno I, Skuratovich A. In Short, What Is TRIZ? http://www.metodolog.ru/01296/01296.html

18.Minaker V. http://www.metodolog.ru/01296/01296.html

19.Saulais $\mathrm{P}$ (2013) Application de la gestion des connaissances à la créativité des experts et à la planification de la R\&T en milieu industriel de haute technologie. Thèse de doctorat, Telecom Ecole de Management

20.Louafa T, Perret F-L (2008) Créativité et Innovation : L'intelligence collective au service du management de projet. LAUSANNE : Presses Polytechniques et Universitaires Romandes

21.Sue N (1990) The Principles of Design. New York, Oxford University Press

22.Fey V \& Rivin E (1997) The Science of Innovation: A Managerial Overview of the TRIZ Methodology. Southield, Michigan

23.Lepot X, Neveux A, Guillou Y \& Baudrux S (2014) "2A2CI, an effective Innovation Methodology that makes TRIZ People \& Business compatible", Global TRIZ Conference 2014, Seoul, Korea

24.Bettencourt L and Ulwick A. (2008) The customer-centered innovation map. Harvard Business Review 86 (5): 109-114

25.Gassmann O., Frankenberger K. \& M. Csik (2014) The Business Model Navigator: 55 Models That Will Revolutionise Your Business. ISBN 9781292065816

26.Mann D (2008) Case Study: Of David's And Goliath's, The TRIZ Journal, March 5, 2008

27.Prevost E, Bruno G, Guillou Y, Sire P \& Conrardy C (2014) "What roles can TRIZ play in Start-up incubators?" Global TRIZ Conference 2014, Seoul, Korea

28.Sire $\mathrm{P}(2016)$ « Objets connectés pour systèmes d'éclairage intelligent - gestion proactive de la lumière », Forum Intelligence économique et stratégique IES 2016, Rouen

29.INPI (2016) La Propriété Intellectuelle et la transformation numérique de l'économie, Consulté le 2211 2016, sur HTTPS://WWW.INPI.FR/FR/SERVICES-ETPRESTATIONS/ETUDE-PI-ET-ECONOMIE-NUMERIQUE 